Supporting Information for

\title{
Tailorable Micelle Morphology in Self-Assembling Block Copolymer Gels for Templating Nanoporous Ceramics
}

John J. Bowen ${ }^{1,2 \#}$, Lisa M. Rueschhoff ${ }^{1 \#}$, Kara L. Martin ${ }^{1,2}$, Dayton P. Street ${ }^{1,3}$,Tulsi A. Patel ${ }^{1,3}$, Maria J. S. Parvulescu ${ }^{1,2}$, Nicholas M. Bedford ${ }^{4}$, Hilmar Koerner ${ }^{1}$, Soenke Seifert ${ }^{5}$, and Matthew B. Dickerson ${ }^{1 *}$

\#denotes equal contributions

*Corresponding author: matthew.dickerson.6@us.af.mil

1. Materials and Manufacturing Directorate, Air Force Research Laboratory, Wright-Patterson AFB, Ohio 45433, United States

2. UES, Inc., Dayton, Ohio 45432, United States

3. NRC Research Associateship Programs, The National Academies, Washington, DC 20001, United States

4. School of Chemical Engineering, University of New South Wales, Sydney, New South Wales 2052, Australia

5. X-ray Sciences Division, Argonne National Laboratory, Argonne, Illinois 60439, United States

Table S1. Average diameter of PMMA-rich region and PnBA/PCS-rich region for various polymer contents

\begin{tabular}{|l|l|l|l|l|}
\hline$\%$ PMMA & $\% \mathrm{PnBa}$ & $\% \mathrm{PCS}$ & $\begin{array}{l}\text { Average PMMA } \\
\text { diameter }(\mathrm{nm})\end{array}$ & $\begin{array}{l}\text { Average PnBa/PCS } \\
\text { diameter }(\mathrm{nm})\end{array}$ \\
\hline 11 & 44 & 45 & $13.6 \pm 2.5$ & $14.7 \pm 2.9$ \\
\hline 30 & 30 & 40 & $13.8 \pm 4.1$ & $14.3 \pm 3.2$ \\
\hline 40 & 20 & 40 & $12.6 \pm 2.0$ & $12.0 \pm 2.3$ \\
\hline
\end{tabular}


Figure S1. SEM images display large spherical agglomerates when 2-ethyl hexanol is not dried prior to gel preparation (A-C). Images are organized in columns where the expected morphology is labeled at the top (e.g., A, D, and G have spherical morphology). To circumvent this issue, 2ethyl hexanol can be dried over activated sieves to prior to use (D-F). AFM images ( 1 x $1 \mu \mathrm{m})$ in G-I confirm thin film morphology and the absence of spherical agglomerates prior to pyrolysis.

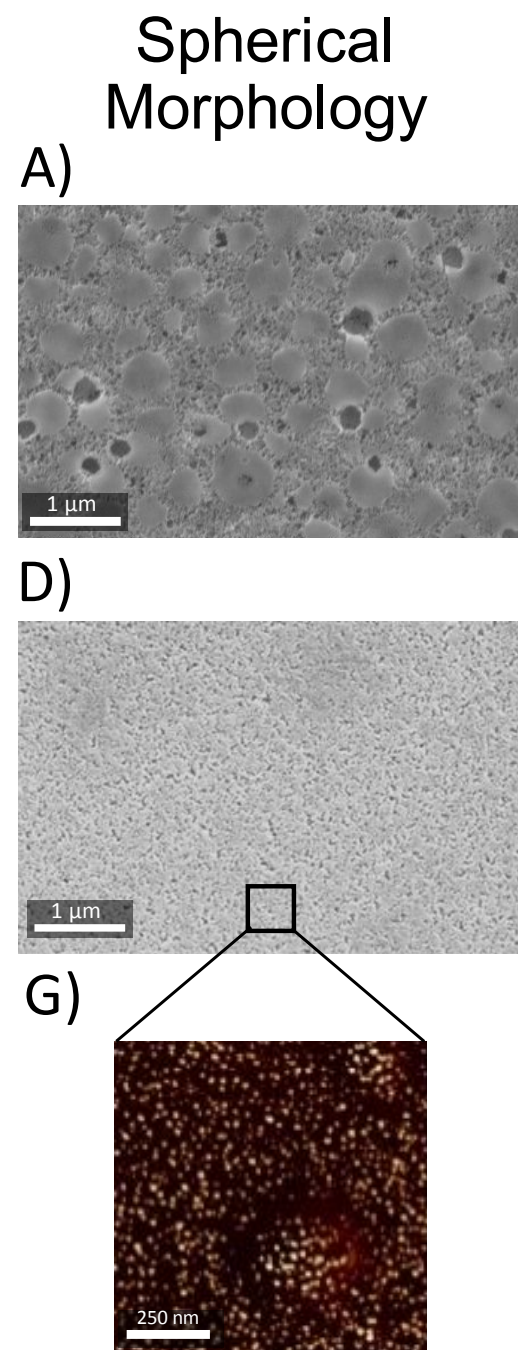

\section{Bicontinuous Morphology}

B)

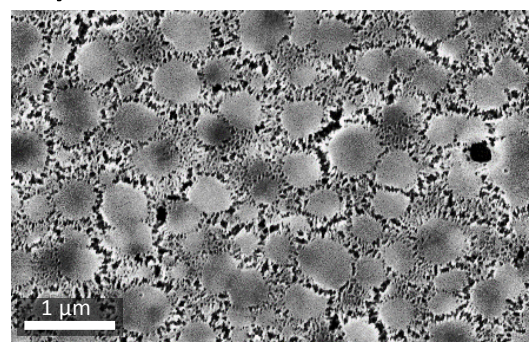

E)

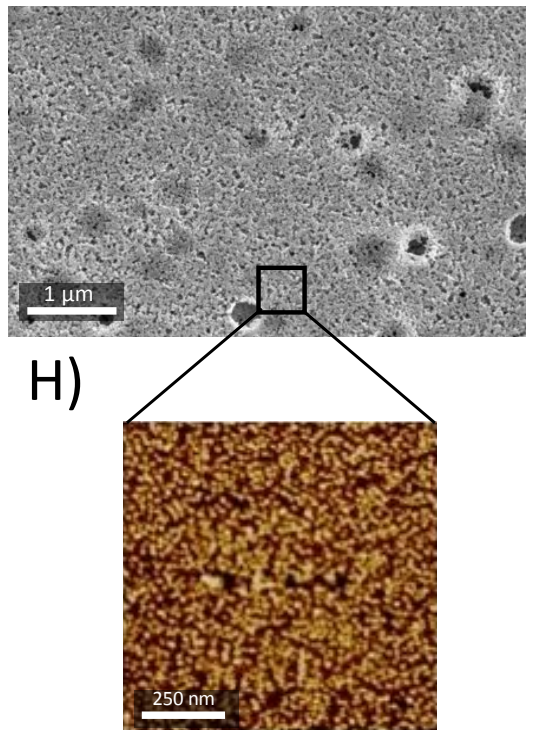

Worm-Like Morphology

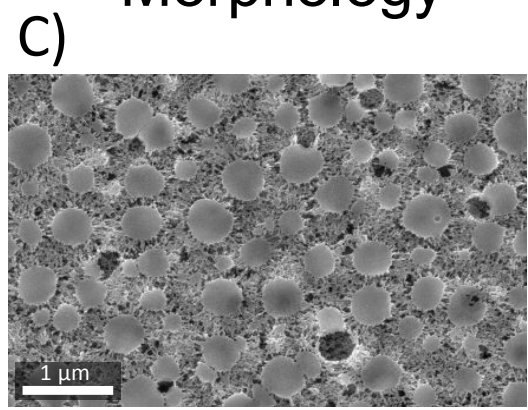

F)

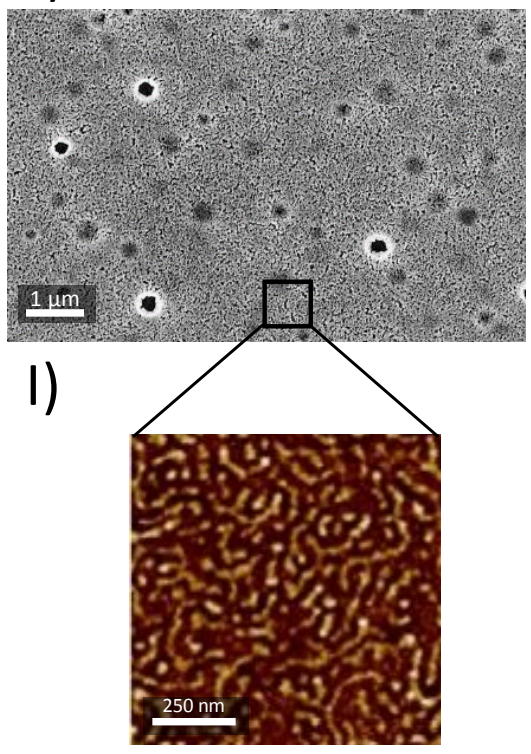


Figure S2. Morphology map with sample numbers corresponding to data given in Table S1. 20:80 PMMA/PnBa BCP (2140) indicated by squares, while 50:50 PMMA/PnBa BCP (4285) is indicated by circles. Spherical morphology is represented in blue, wormlike morphology is represented in red, and bicontinuous morphology is represented in green. Morphologies previously reported are marked with an asterisk.

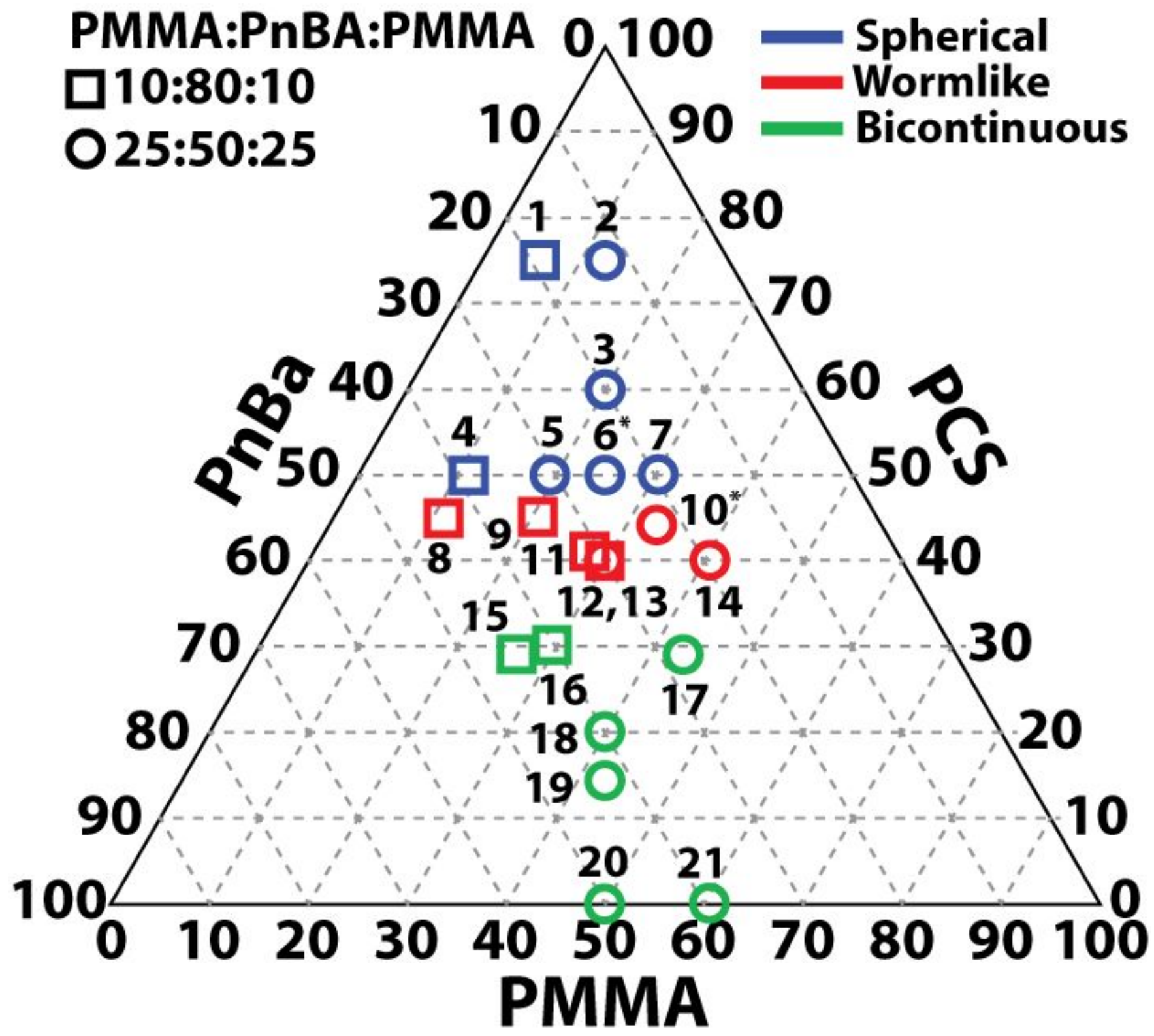


Figure S3. AFM micrographs from each of the listed samples in the morphology map. Scale bars $100 \mathrm{~nm}$.

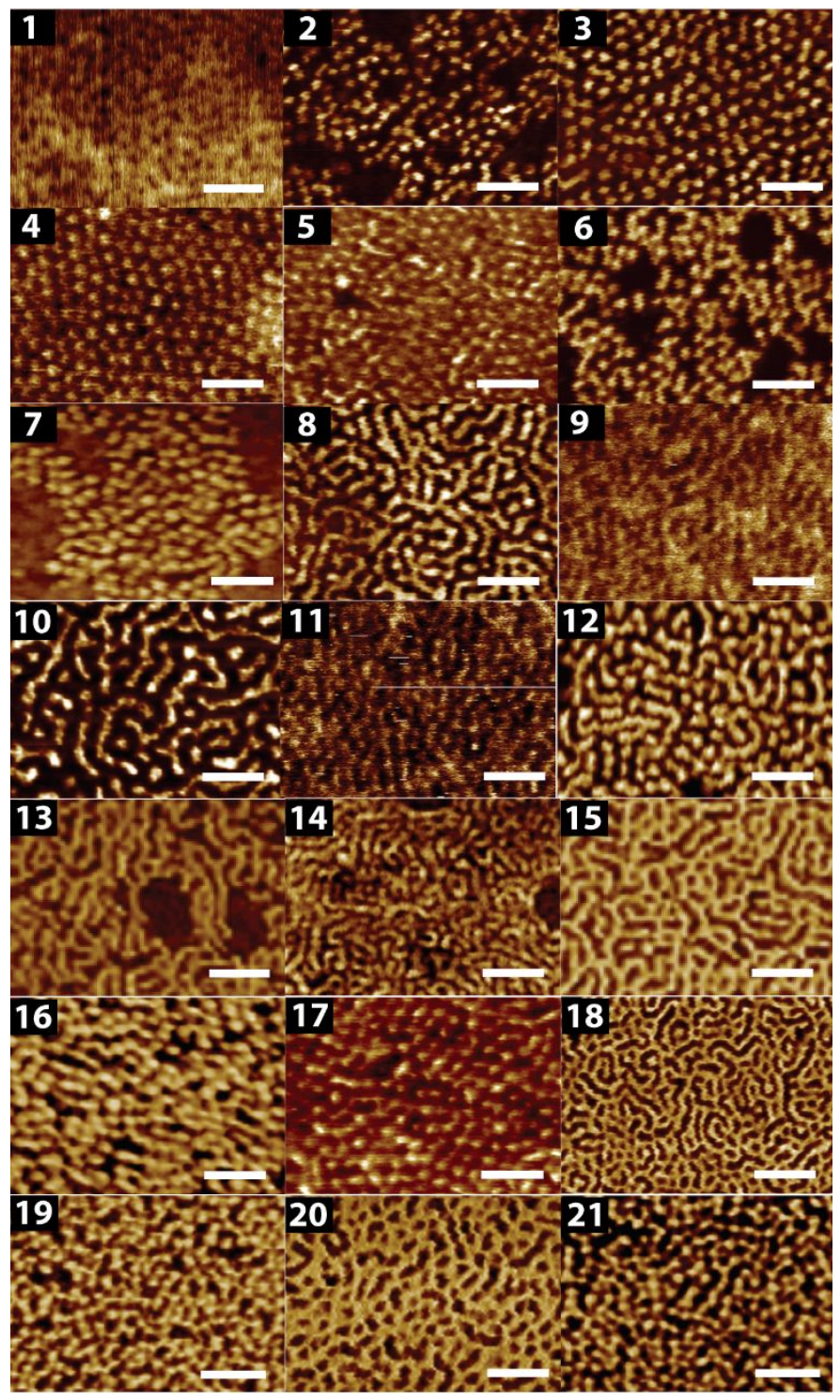


Figure S4. AFM images of wormlike morphologies from 40\% PCS and 30\% PMMA, with PMMA from A) BCP only (Sample 12) and B) BCP and homopolymer (Sample 13).
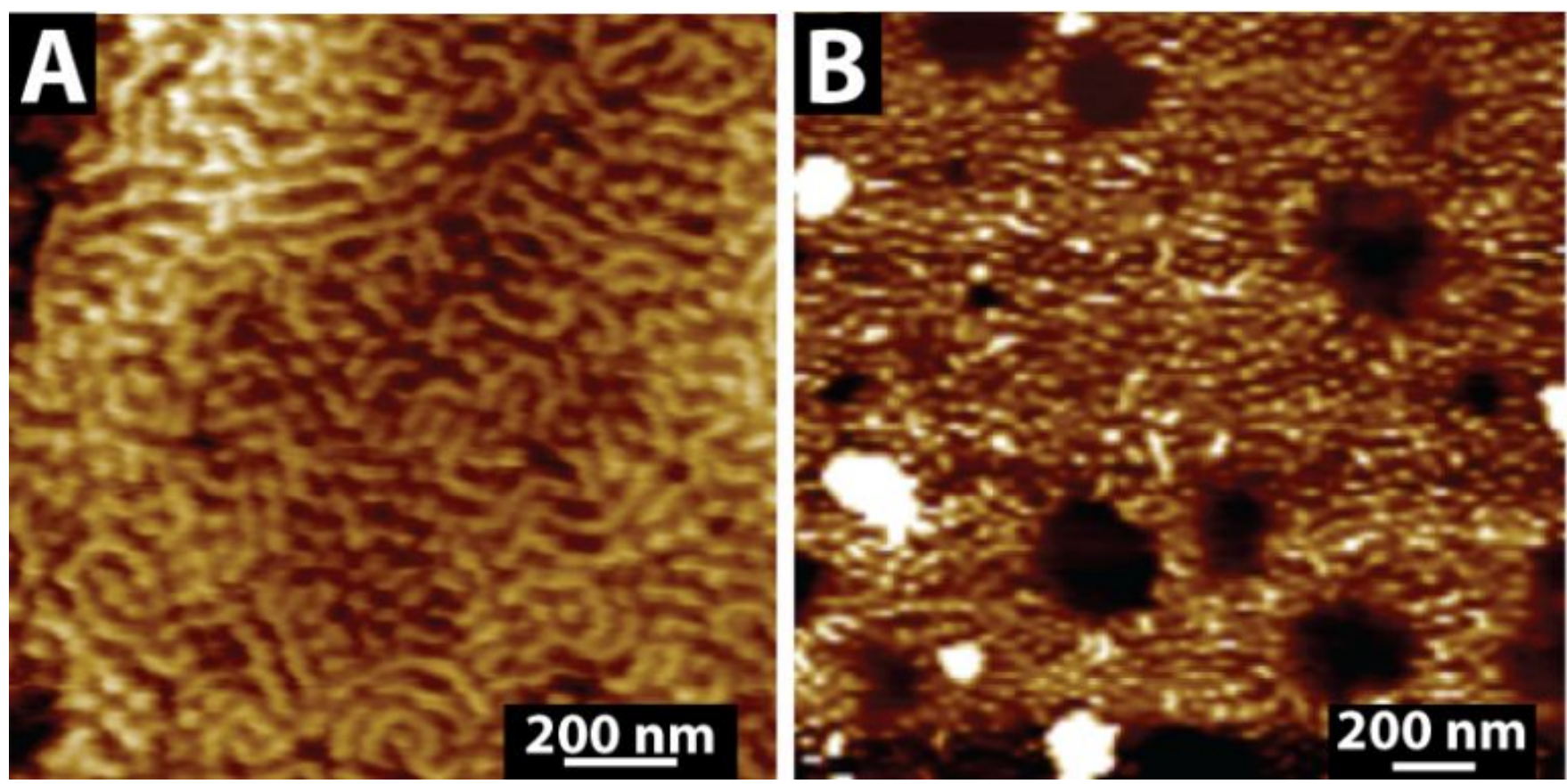
Figure S5. SAXS results are shown as temperature decreases for representative A) spherical (Sample 6), B) wormlike (Sample 10), and C) bicontinuous (Sample 17) morphology gels.

Temperatures are indicated by color: $25^{\circ} \mathrm{C}$ (black), $41^{\circ} \mathrm{C}$ (yellow), $51^{\circ} \mathrm{C}$ (orange), and $65^{\circ} \mathrm{C}$ (red).
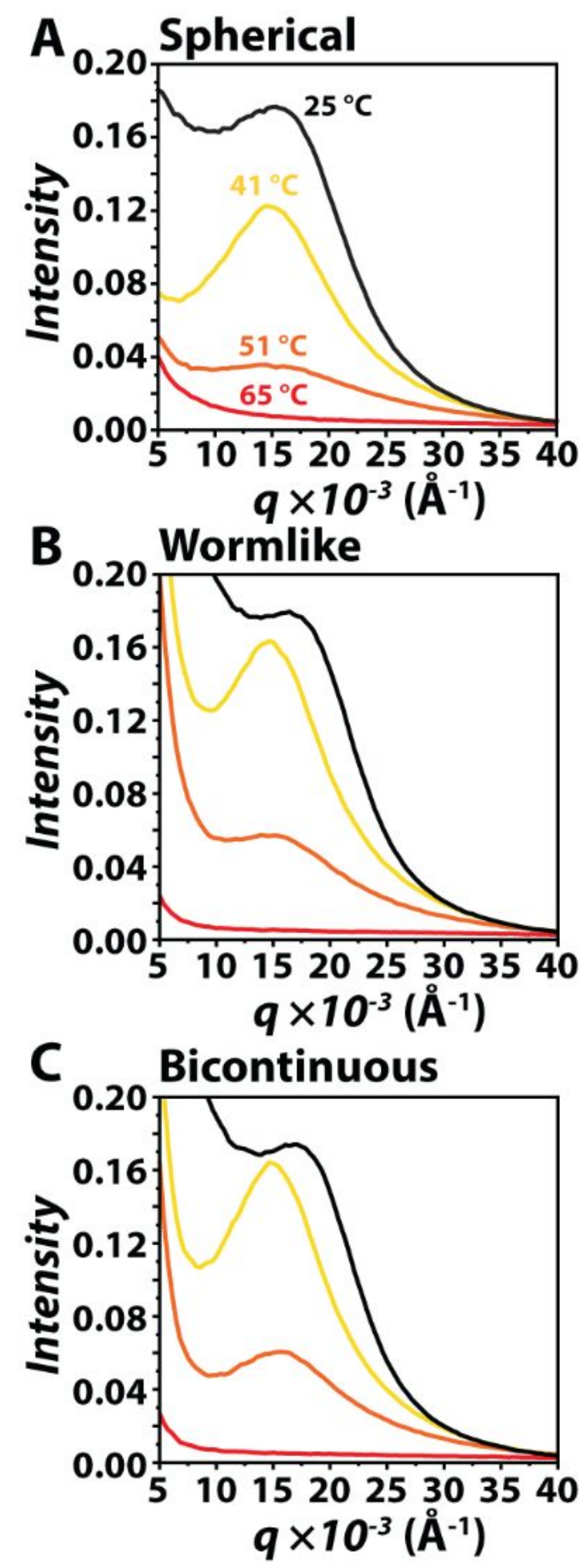
Figure S6. Distribution of pore sizes in A) spherical, B) wormlike, and C) bicontinuous micelle gel-derived ceramic samples. Images D-F represent expanded views of small pore area regions of frequency graphs for A-C, respectively.
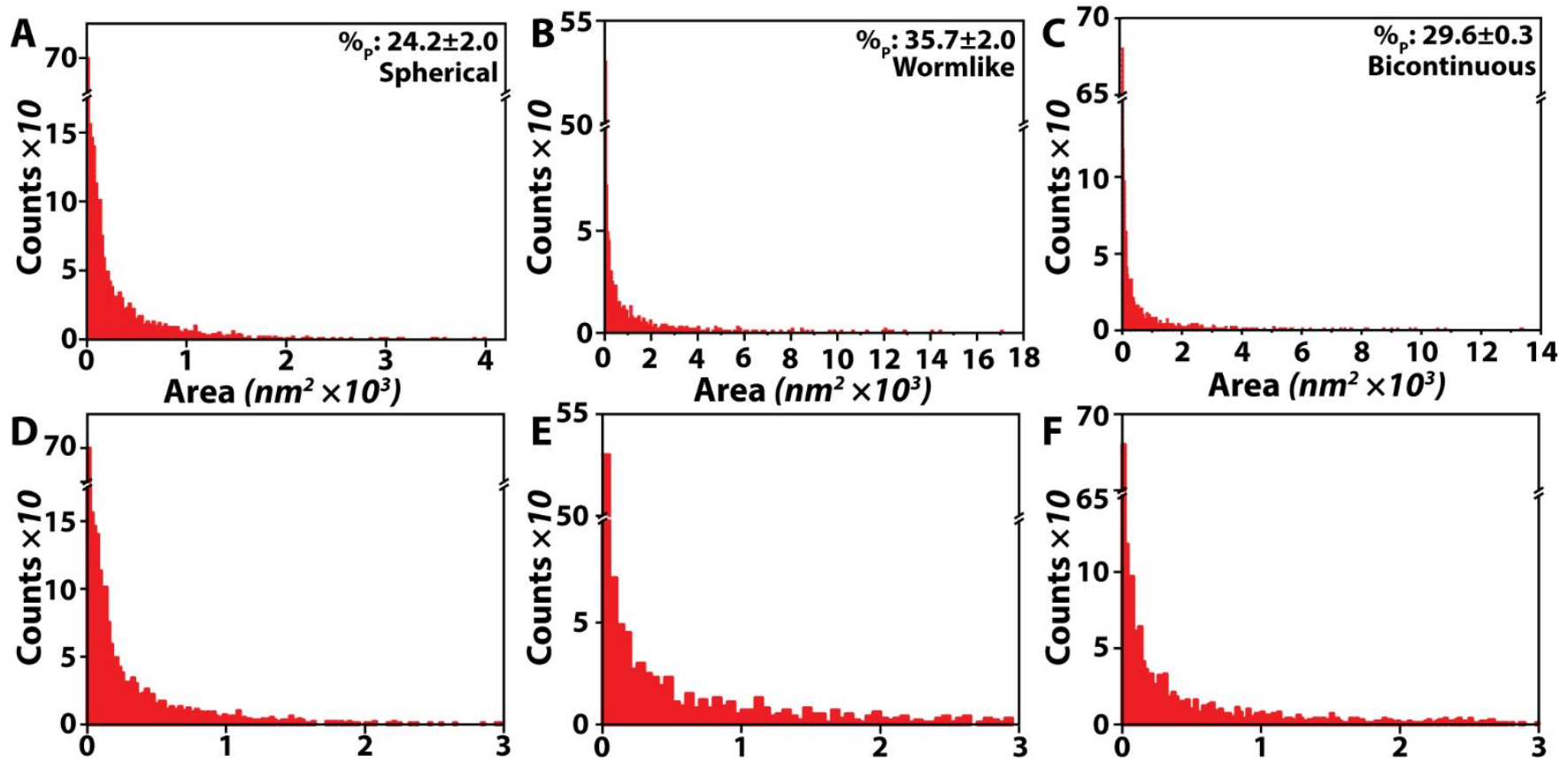
Figure S7. Area percent (Area\% PMMA $_{\text {) }}$ of PMMA in AFM micrographs and $\mathrm{wt} \% \mathrm{PCS}$ (Wt $\%_{\mathrm{PCS}}$ ) for A) spherical (Sample 3), B) wormlike (Sample 10), and C) bicontinuous (Sample 19). Scale bars are $100 \mathrm{~nm}$.

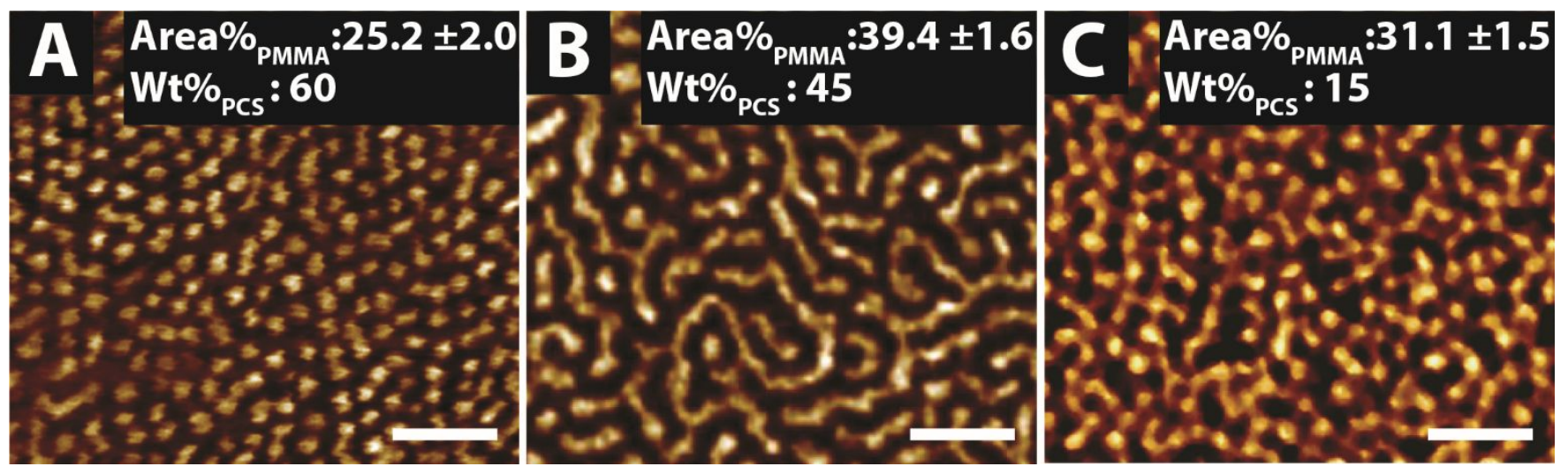


Figure S8. XPS plot of a nanocoral film (Sample 10) using monochromatic Al Ka X-rays with an energy of $1486.6 \mathrm{eV}$.

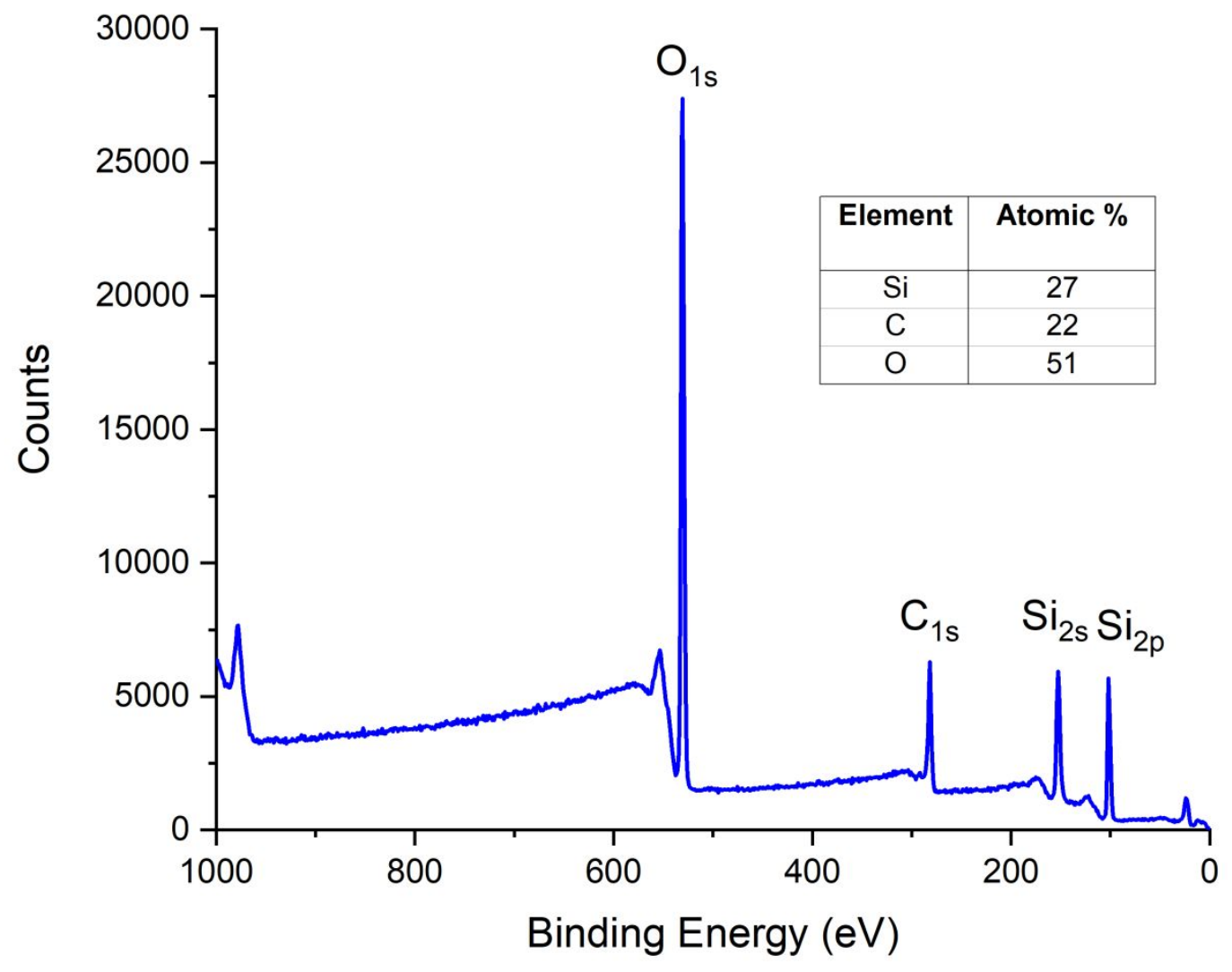

